Article

\title{
Genetic Transformation and Green Fluorescent Protein Labeling in Ceratocystis paradoxa from Coconut
}

\author{
Xiaoqing Niu ${ }^{1,2}{ }^{\oplus}$, Mengtian Pei ${ }^{1}$, Chenyu Liang ${ }^{1}$, Yuexiao Lv ${ }^{1}$, Xinyi Wu ${ }^{1}$, Ruina Zhang ${ }^{1}$, \\ Guodong $\mathrm{Lu}^{1}{ }^{1} * \mathbb{C}$, Fengyu $\mathrm{Yu}^{2}$, Hui $\mathrm{Zhu}{ }^{2}$ and Weiquan Qin ${ }^{2}$ \\ 1 Key Laboratory of Biopesticide and Chemical Biology, Ministry of Education, Fujian Agriculture and \\ Forestry University, Fuzhou 350002, China; xiaoqingniu123@126.com (X.N.); 15870651077@163.com (M.P.); \\ liangcy@163.com (C.L.); lyuyuexiao513@163.com (Y.L.); Yimi1207@163.com (X.W.); \\ 18838933694@126.com (R.Z.) \\ 2 Coconut Research Institute, Chinese Academy of Tropical Agricultural Sciences, Wenchang 571339, China; \\ yufengyu17@163.com (F.Y.); zhuhui@catas.cn (H.Z.); qwq268@163.com (W.Q.) \\ * Correspondence: lgd@fafu.edu.cn; Tel.: +86-0591-83789478
}

Received: 10 April 2019; Accepted: 11 May 2019; Published: 14 May 2019

\begin{abstract}
Ceratocystis paradoxa, the causal agent of stem-bleeding disease of the coconut palm, causes great losses to the global coconut industry. As the mechanism of pathogenicity of C. paradoxa has not been determined, an exogenous gene marker was introduced into the fungus. In this study, pCT74-sGFP, which contains the green fluorescent protein (GFP) gene, and the hygromycin B resistance gene as a selective marker, was used as an expression vector. Several protoplast release buffers were compared to optimize protoplast preparation. The plasmid pCT74-sGFP was successfully transformed into the genome of $C$. paradoxa, which was verified using polymerase chain reaction and green fluorescence detection. The transformants did not exhibit any obvious differences from the wild-type isolates in terms of growth and morphological characteristics. Pathogenicity tests showed that the transformation process did not alter the virulence of the X-3314 C. paradoxa strain. This is the first report on the polyethylene glycol-mediated transformation of $C$. paradoxa carrying a 'reporter' gene GFP that was stably and efficiently expressed in the transformants. These findings provide a basis for future functional genomics studies of C. paradoxa and offer a novel opportunity to track the infection process of $C$. paradoxa.
\end{abstract}

Keywords: stem-bleeding disease of coconut; Ceratocystis paradoxa; gfp gene; transformation; protoplast

\section{Introduction}

Coconut palm (Cocos nucifera L.) is one of the most economically important trees in the world. It generates employment and income in many countries, where its fruit is either eaten raw or processed into manufactured products and by-products. However, coconut production is affected by many biotic and abiotic factors. Coconut stem-bleeding (CSB), caused by the fungus Ceratocystis paradoxa (De Seynes) Höhn (anamorph Thielaviopsis paradoxa), is one of the most notorious biotic diseases of coconut. CSB is known to occur in coconut-producing areas worldwide. The disease was first reported in Sri Lanka [1] and caused severe damage to PB-121 hybrids in Indonesia. In the state of Sergipe, Brazil, it was first detected in early 2004 [2]. It was discovered in China for the first time in 2009, where it was found to occur in nearly all coconut gardens [3]. The disease has gradually become the primary concern of producers and researchers due to its rapid spread and great lethality to coconut. Affected plants perish within 3-4 months after the first appearance of stem symptoms. 
The symptoms of CSB are described as follows: The affected trunk areas exhibit dark discoloration and a reddish-brown or rust-colored liquid bleeding from the stem cracks that may turn blackish when dried, resulting in rotting when moist; there is a reduced frequency of leaf emergence and a reduced young leaf size, with stem-thinning occurring near the canopy as the disease progresses; and the leaves eventually become brownish-yellow and fragile [2,3]. Besides the trunk and leaves, C. paradoxa also infects the coconut fruit, with the infected pericarp becoming black and soft and producing a strong fruity aroma [4].

The ascomycete C. paradoxa not only infects palm trees, such as Cocos nucifera, Phoenix dactylifera, Borassus flabellifer, Butia capitata, Elaeis guineensis, and Areca catechu, but also infects other plants, including Ananas comosus, Mangifera indica, Musa paradisiaca, Solanum muricatum, Theobroma cacao, and Zea mays, resulting in large agricultural losses [3]. The biological characteristics of the pathogen have thus far been described [5], and the partial and temporal dynamics of stem-bleeding have been recorded for clarifying the disease progression and characterizing the production losses from the disease [6]. In addition, some CSB disease management studies have been reported, including physical, chemical, and biological control measures [7-10]. However, a detailed understanding of the pathogenesis and infection dynamics of this pathogen is lacking. While a previous report on the transformation of C. paradoxa using Agrobacterium exists [11], the pathogenesis of C. paradoxa was not explored.

Highly efficient transformation would be beneficial for a detailed investigation of the infection characteristics and pathogenesis of $C$. paradoxa and its interaction with the host. Green fluorescent protein (GFP) expression has proven to be a useful tool for such analyses in filamentous fungi $[12,13]$ and has been successfully expressed in numerous ascomycetes, including Colletotrichum acutatum, Verticillium fungicola Acremonium chrysosporium, and Sordari macrospora $[14,15]$. In this study, the first protoplast preparation and polyethylene glycol (PEG)-mediated transformation system for C. paradoxa was established, and the expression vector PCT74-sGFP was transformed into the fungus to obtain a recombinant fungus labeled with GFP. Our protocol will inform research that involves monitoring the infection progression of this fungus in the coconut and should also inform the further exploration of the mechanisms of $C$. paradoxa pathogenicity.

\section{Results}

\subsection{Sensitivity of C. paradoxa to $H m B$}

Hyphal inocula of the wild-type strain X-3314 were inoculated on potato dextrose agar (PDA) plates containing different concentrations of hygromycin $\mathrm{B}(\mathrm{HmB})$. After five days, the fungus continued to grow on the plates when the concentration of $\mathrm{HmB}$ remained below $30 \mu \mathrm{g} / \mathrm{mL}$, but failed to grow at concentrations higher than $40 \mu \mathrm{g} / \mathrm{mL}$ (Figure 1). Thus, $30 \mu \mathrm{g} / \mathrm{mL} \mathrm{HmB}$ could markedly inhibit the growth of $C$. paradoxa, while $40 \mu \mathrm{g} / \mathrm{mL} \mathrm{HmB}$ completely inhibited growth. PDA containing $40 \mu \mathrm{g} / \mathrm{mL}$ $\mathrm{HmB}$ was therefore used to screen for successful transformants carrying a functional $h p h$ gene. In this study, each plate consisted of $10 \mathrm{~mL}$ PDA with $2 \mu \mathrm{L}, 4 \mu \mathrm{L}, 6 \mu \mathrm{L}, 8 \mu \mathrm{L}$ of $\mathrm{HmB}(1 \mathrm{~g} / 20 \mathrm{~mL})$, resulting in final concentrations of $\mathrm{HmB}$ of $10 \mu \mathrm{g} / \mathrm{mL}, 20 \mu \mathrm{g} / \mathrm{mL}, 30 \mu \mathrm{g} / \mathrm{mL}$, and $40 \mu \mathrm{g} / \mathrm{mL}$.

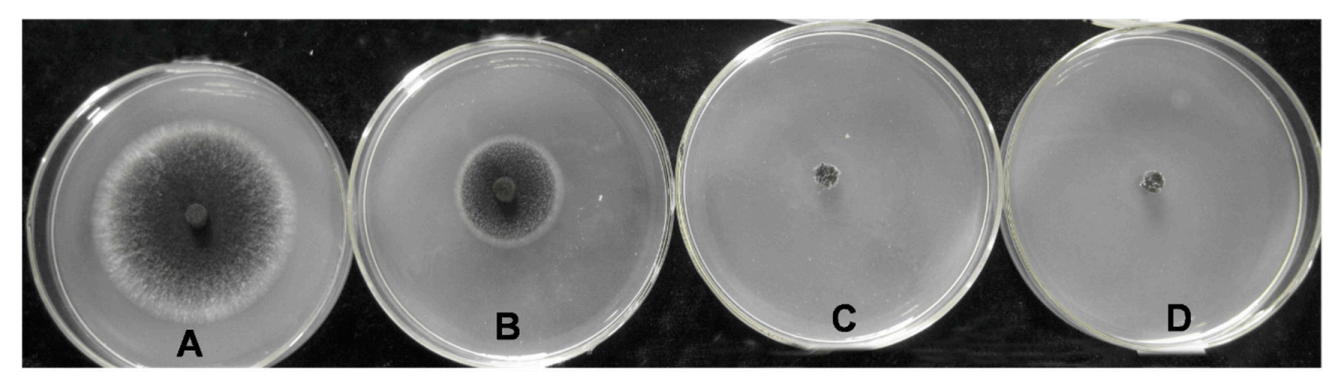

Figure 1. The growth of C. paradoxa on PDA medium with $\mathrm{HmB} 10 \mathrm{ug} / \mathrm{mL},(\mathbf{A}) ; 20 \mathrm{ug} / \mathrm{mL},(\mathbf{B}) ; 30 \mu \mathrm{g} / \mathrm{mL}$, (C); $40 \mu \mathrm{g} / \mathrm{mL},(\mathbf{D})$. 


\subsection{Protoplast Preparation}

Following digestion with protoplast release buffer 2 at $31^{\circ} \mathrm{C}$ for $30 \mathrm{~min}$, the mycelia began to rupture and single cells could be observed. Sufficient protoplasts began to form after an additional $1 \mathrm{~h}$ of digestion (Figure 2), with the concentration reaching $3.0 \times 10^{9}$ spores $\mathrm{mL}^{-1}$. Compared with this protoplast release buffer, the quantity of protoplasts obtained using the other protoplast release buffers (buffers 1, 3, 4, 5, and 6) was far below $3.0 \times 10^{9}$. Furthermore, the other buffers proved time-consuming and wasteful.

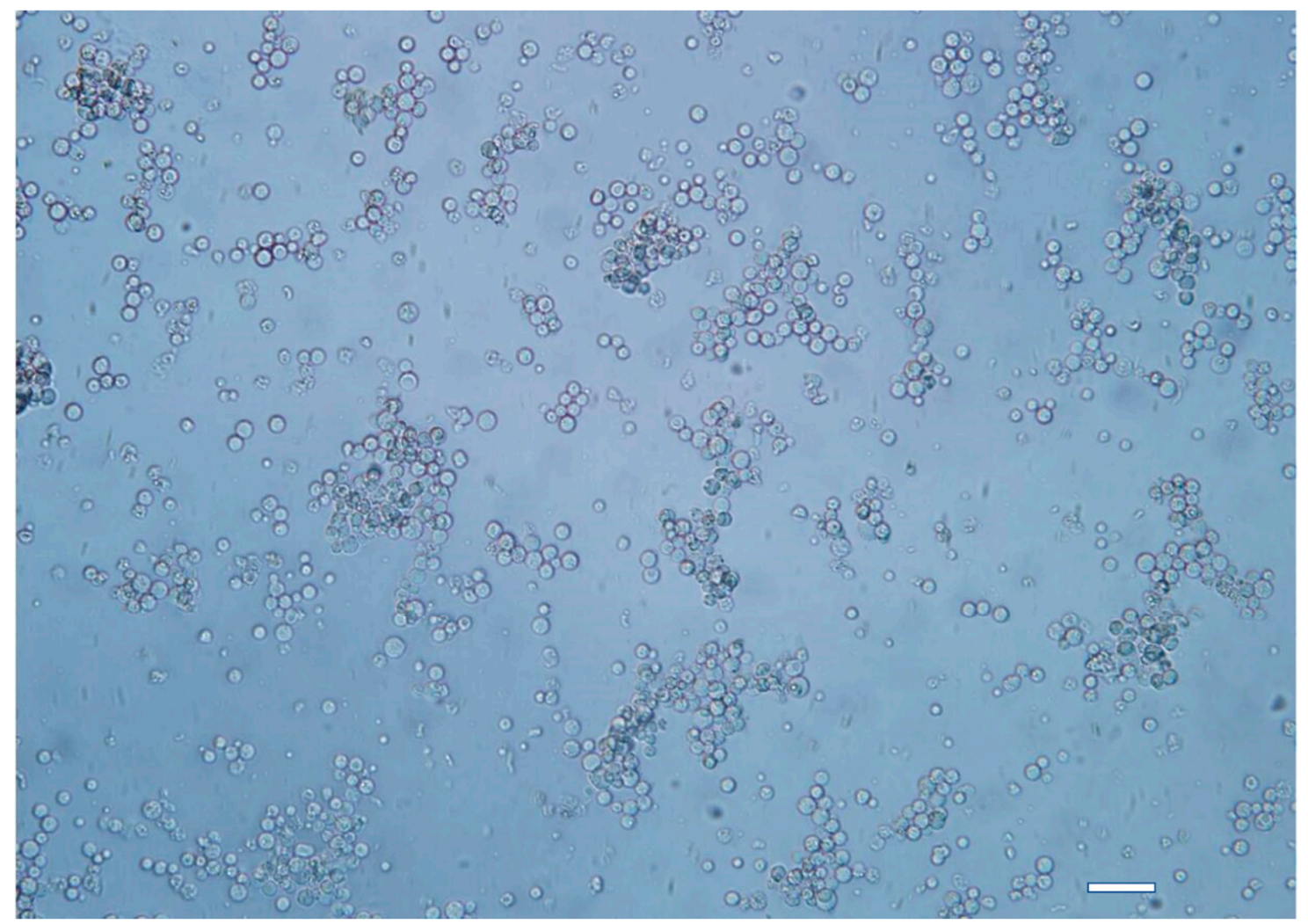

Figure 2. The mycelia were digested in protoplast release buffer 2 at $31^{\circ} \mathrm{C}$ with shaking for $1.5 \mathrm{~h}$. Sufficient protoplasts formed thereafter, with concentrations reaching $3.0 \times 10^{9}$ spores $\mathrm{mL}^{-1}$. Bar: $100 \mu \mathrm{m}$.

\subsection{Screening and Detection of Transformants}

The C. paradoxa transformants were selected using $100 \mathrm{~mL}$ of selective medium containing $80 \mu \mathrm{L}$ of $1 \mathrm{~g} / 20 \mathrm{~mL} \mathrm{HmB}$. Five days after transformation, the transformants were inoculated on fresh PDA plates containing $160 \mu \mathrm{L}$ of $1 \mathrm{~g} / 20 \mathrm{~mL} \mathrm{HmB}$. Together with the results of several transformation cases, the average transformation efficiency was $4 \sim 5$ transformants per $\mu \mathrm{g}$ DNA. Four transformants $(\mathrm{X} 1, \mathrm{X} 2, \mathrm{X} 3$, and X4) were selected for further study. These four transformants could grow normally on CM plates containing $16 \mu \mathrm{L}$ of $1 \mathrm{~g} / 20 \mathrm{~mL} \mathrm{HmB}$. Whereas the wild-type failed to grow (Figure 3 ), the plates contained $10 \mathrm{~mL} \mathrm{CM}$, which indicated that the four transformants possessed the hygromycin $B$ resistance gene. The colonies and hyphal morphology of the four transformants were almost identical to the wild-type. After subculturing seven times on PDA plates lacking HmB, the four transformants were still able to grow on the HmB PDA plate. This suggested that all four transformants exhibited genetic stability.

The $\mathrm{X} 1, \mathrm{X} 2, \mathrm{X} 3$, and $\mathrm{X} 4$ transformants showed strong fluorescence when observed under the confocal microscope (Figure 4), and their fluorescence remained genetically stable after seven subcultures on PDA medium. This result suggested that the GFP gene could be stably expressed in C. paradoxa. 


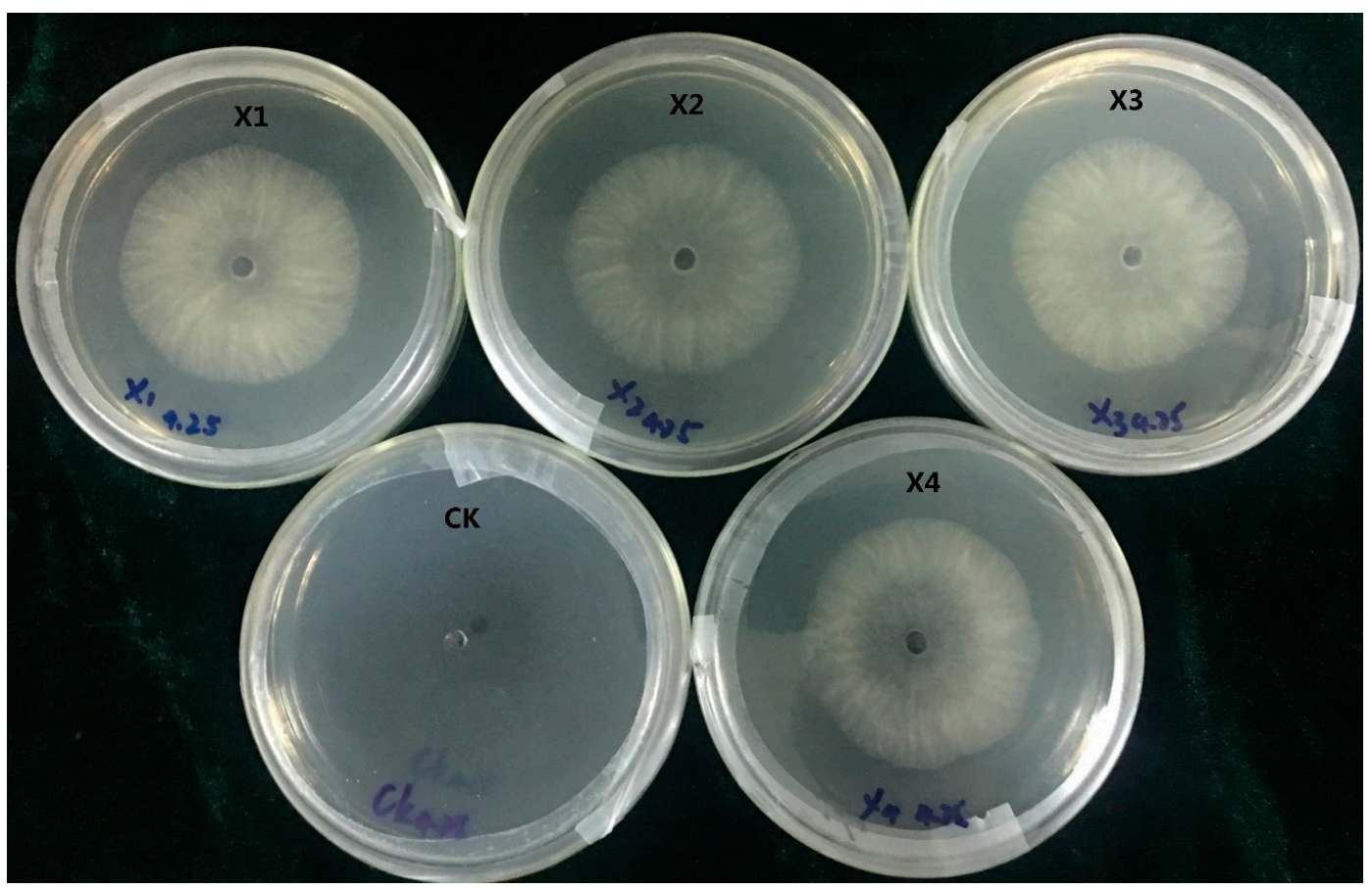

Figure 3. The growth of the transformants on HmB plates. (CK), wild-type strain X-3314; (X1-X4), transformants. The transformants and wild-type strain were cultured on PDA plates containing $16 \mu \mathrm{L}$ of $1 \mathrm{~g} / 20 \mathrm{~mL} \mathrm{HmB}$, respectively. The figure shows that the transformant strains (X1-X4) could grow on PDA plates, while the wild-type failed to grow.

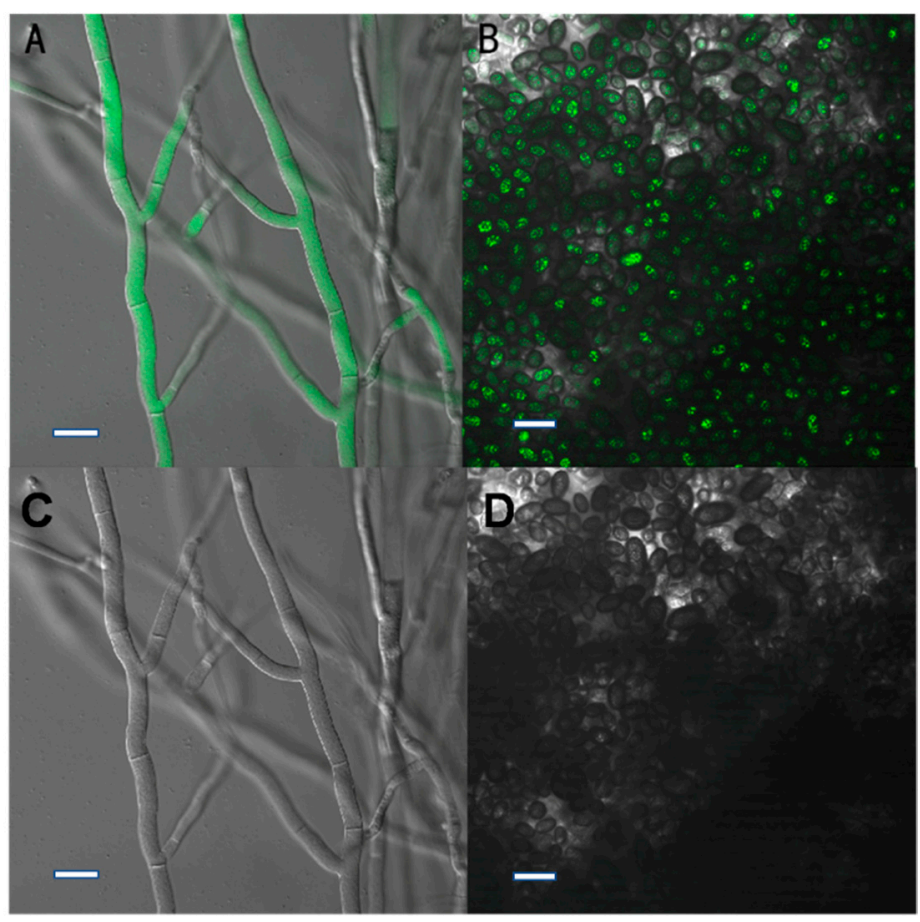

Figure 4. Expression of GFP in the transformants. (A,B), green fluorescence was observed in the mycelia and conidia of transformant X1 using a confocal microscope; (C,D), the mycelia and conidia in visible light. Bars: A-D $=10 \mu \mathrm{m}$. 


\subsection{PCR Confirmation of the Transformants}

To verify that the GFP gene had been integrated into the genome, the genomic DNA of $\mathrm{X} 1, \mathrm{X} 2, \mathrm{X} 3$, and X4 was amplified using the ToxAsGFPF/ToxAsGFPR primers. The predicted $1130 \mathrm{bp}$ fragment was amplified from the transformants and plasmid control, but never from the wild-type strain. This indicated that the GFP gene had been integrated into the C. paradoxa transformants.

\subsection{Pathogenicity Detection of the Transformants}

The GFP-labeled transformants were used to infect wounded coconut fruits. Three days after inoculation, characteristic disease symptoms appeared on the fruits that had been inoculated with the wild-type strain X-3314, as well as the X1, X2, X3, and X4 transformants (Figure 5). The C. paradoxa X-3314 strain and the transformants were re-isolated successfully from the diseased tissues. Additionally, the isolated transformants still exhibited strong green fluorescence (Figure 6). These findings suggest that the transformants can be used to study the infection process of this fungus.
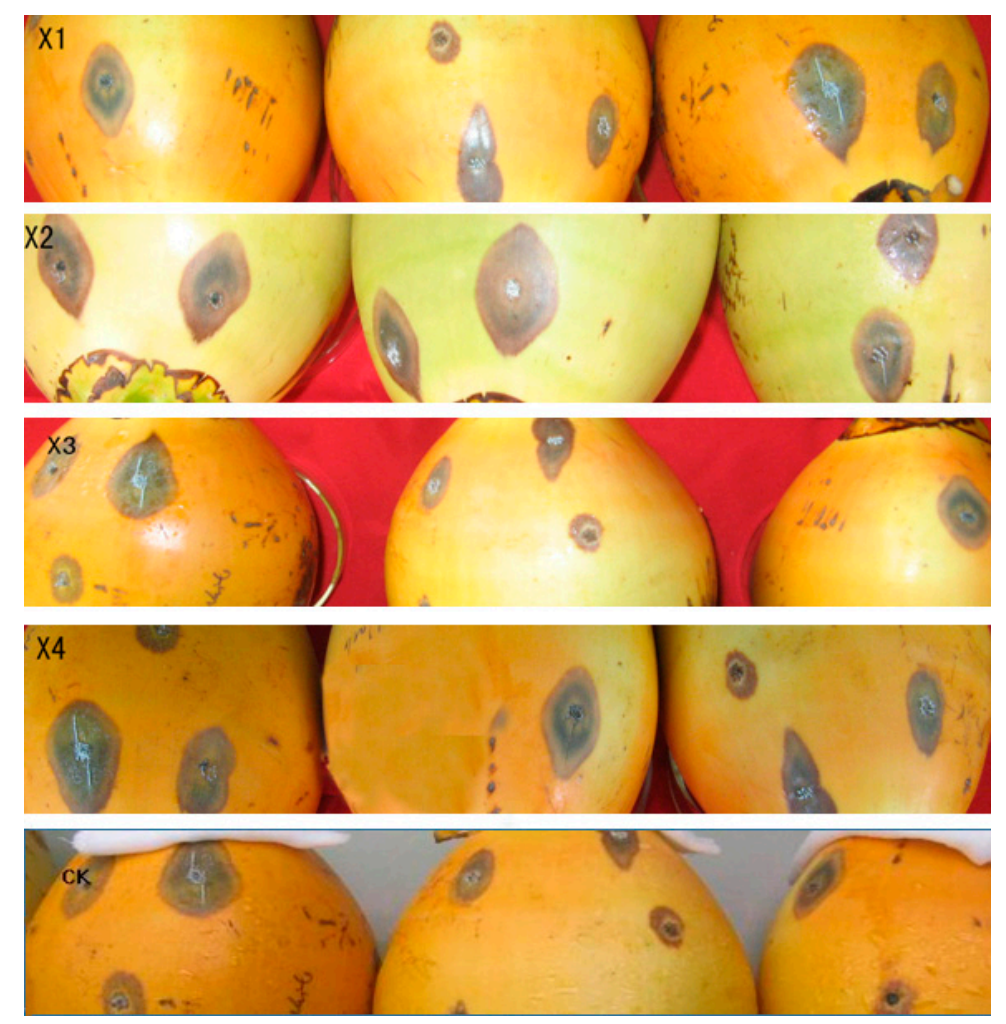

Figure 5. Pathogenicity detection of the transformants. Symptoms of coconut stem-bleeding disease on coconut fruits after wound-inoculating $1.5 \times 10^{5}$ spores $\cdot \mathrm{mL}^{-1}$ suspension of transformants $(\mathbf{X 1}-\mathbf{X} 4)$, respectively, for 3 days. CK: wild-type strain $\mathrm{X}-3314$ was used as a control. 


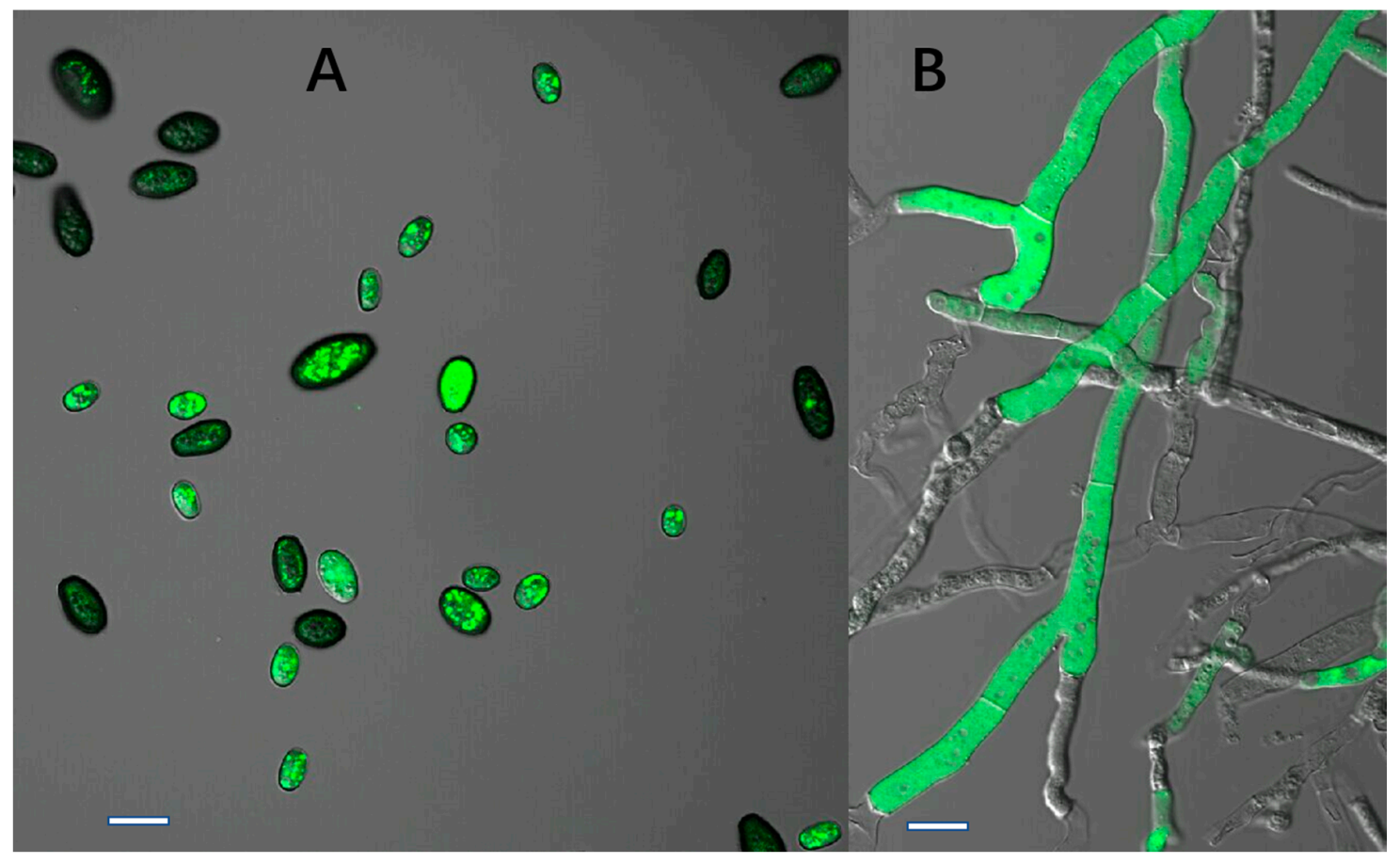

Figure 6. The isolated transformants exhibited strong green fluorescence in hypha and conidia. Bars: $(\mathbf{A}, \mathbf{B})=10 \mu \mathrm{m}$.

\section{Discussion}

As the causal agent of coconut stem-bleeding (CSB), C. paradoxa causes great economic losses to the coconut industry. Understanding the invasion, colonization, and localization mechanisms of C. paradoxa in coconut could facilitate the development of new strategies for disease control in the future. In the present study, we successfully transformed the hygromycin B resistance gene and a 'reporter' gfp gene into C. paradoxa, obtaining stable transformants of $C$. paradoxa that efficiently expressed GFP.

Protoplast quantity is one of the key factors influencing transformation efficiency. The results of this study demonstrated that transformants were rarely obtained when the number of protoplasts was lower than $1 \times 10^{6} / \mathrm{mL}^{-1}$. This corroborates the consensus that a high concentration of protoplasts is required for successful transformation $[16,17]$. The concentration of the plasmid pCT74-sGFP also influenced the transformation results, with $500 \mathrm{ng} / \mu \mathrm{L}$ of pCT74-sGFP means approximately $2 \mu \mathrm{g}$ of DNA being required. Thus, the preparation of a sufficient quantity of protoplasts is necessary for successful transformation, but a high plasmid concentration is equally important.

Due to fungal cell wall differences, the enzyme type and digestion conditions can affect protoplast production. In this study, the cell wall of $C$. paradoxa was digested with different protoplast release buffers at the same temperature $\left(31^{\circ} \mathrm{C}\right)$, but the duration of the treatment and the quantity of the protoplasts obtained differed between the buffers. A comparison of the six treatment results indicated that adequate protoplasts could only be obtained after digestion with protoplast release buffer 2 for $90 \mathrm{~min}$, while the other treatments (protoplast release buffer 1,3, 4, 5, and 6) were either overly time-consuming or produced lower yields.

After subculturing seven times on PDA plates lacking $\mathrm{HmB}$, the four transformants $(\mathrm{X} 1, \mathrm{X} 2, \mathrm{X} 3$, and X4) could still grow on HmB PDA plates and exhibited high green fluorescence inside the hyphae and conidia, which is indicative of genetic stability. The results indicated that the $g f p$ gene had been successfully transformed into C. paradoxa. Furthermore, the pathogenicity test demonstrated that the transformants caused typical disease symptoms that were the same as the wild-type strain, which suggested that the pathogenicity of the transformant strain had not changed. This verified that they can be used for studying C. paradoxa infection in coconut palms. 
GFP as a reporter has been widely used in fungi [18-20]. The advantage of real-time observation renders it a great tool for the analysis of living cells and organisms. However, its application is limited in plant pathogen analyses due to the lower number of transformed species or inefficient expression and low fluorescence [21]. The successful expression of GFP is usually based on a stronger promoter or a high copy number viral vector [22]. The ToxA promoter has proven valuable for the strong expression of GFP in ascomycetes with diverse lifestyles [23]. Our results indicated that this promoter can be used to obtain high GFP expression in C. paradoxa.

This study is the first to report on GFP expression in C. paradoxa. The transformants can be used for the study of fungal colonization, localization, and invasion in plants. Furthermore, the protoplast preparation and transformation method described here can be used as a tool for efficiently constructing a random insertional transformant library, gene functional analysis, and the exploration of the pathogenic mechanisms of C. paradoxa.

\section{Materials and Methods}

\subsection{Strain and Plant Material}

The C. paradoxa X-3314 strain (Collection No. CCTCC AF2014002) was isolated from an infected coconut stem and stored at the Coconut Research Institute of Chinese Academy of Tropical Agricultural Sciences (Wenchang, Hainan province, China). The Escherichia coli strain DH5a was used in this study. The plant material was coconut fruits of "Malayan Red Dwarf".

\subsection{Fungal Transformation Vector}

A pCT74-sGFP plasmid (Figure 7) was constructed and stored at the Functional Genomics Center, Fujian Agriculture and Forestry University. The transformation construct relies on antibiotic resistance conferred by a modified form of the E. coli hygromycin B phosphotransferase (hph) gene for transformation selection [24]. PCT74 further employs the necrosis-inducing host-selective toxin gene ToxA promoter from Pyrenophoratritici repentis to drive the expression of the synthetic GFP genes (sGFP) [22,25].

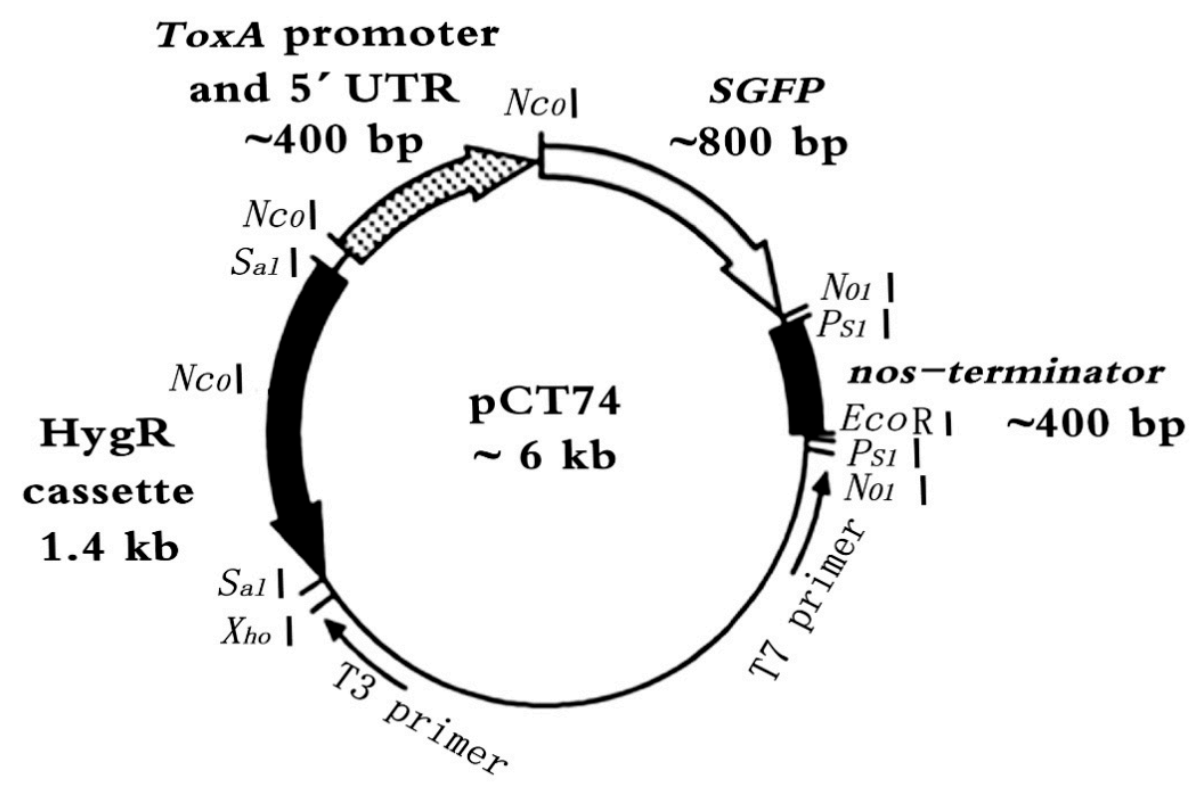

Figure 7. Map of expression vector for filamentous fungi pCT74-sGFP.

\subsection{Media and Reagents}

The media used in this test included complete liquid medium (CM) (6 g yeast extract, $10 \mathrm{~g}$ sucrose,

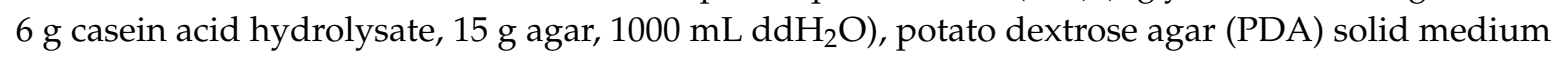




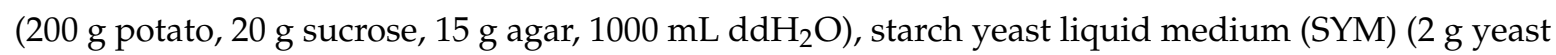

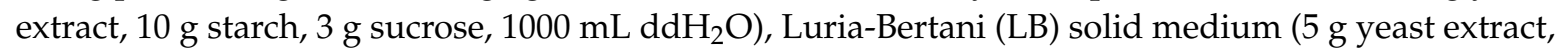

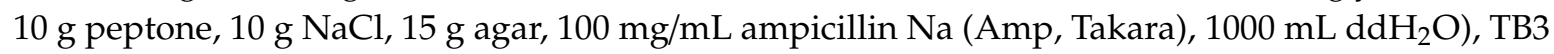

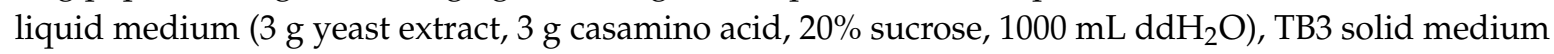

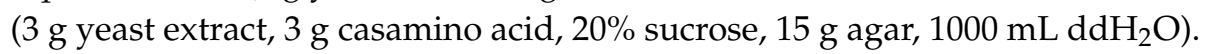

STC buffer (44 g sorbitol, $10 \mathrm{~mL} 1.0 \mathrm{~mol} / \mathrm{L}$ Tris-HCL (pH 8.0), $10 \mathrm{~mL} 1 \mathrm{~mol} / \mathrm{L} \mathrm{CaCl}_{2}, 200 \mu \mathrm{L}$ streptomycin, add $\mathrm{ddH}_{2} \mathrm{O}$ up to $200 \mathrm{~mL}$, and sterile water filtered through a $0.22-\mu \mathrm{m}$ filter (Jet Biofil FPV203000)). PTC buffer (4 g PEG3350, $10 \mathrm{~mL} \mathrm{STC,} 10 \mu \mathrm{L}$ streptomycin nitrate, heat-dissolved at $60^{\circ} \mathrm{C}$ for $20 \mathrm{~s}$ and sterile filtered), osmotic pressure stabilizer $(1.0 \mathrm{~mol} / \mathrm{L}$ mannitol, $1.0 \mathrm{~mol} / \mathrm{L}$ sorbitol), protoplast release buffer 1 (1\% lysing enzyme (Sigma-Aldrich, St. Louis, MO, US, CB8709259) with $1.0 \mathrm{~mol} / \mathrm{L}$ mannitol); protoplast release buffer 2 (1\% Driselase (Sigma-Aldrich, cat. No. CB0296810) with $1.0 \mathrm{~mol} / \mathrm{L}$ mannitol in STC); protoplast release buffer 3 (mixture of $1 \%$ Driselase and $1 \%$ lysing enzyme with $1.0 \mathrm{~mol} / \mathrm{L}$ mannitol in STC); protoplast release buffer 4 (1\% lysing enzyme with $1.0 \mathrm{~mol} / \mathrm{L}$ sorbitol in STC); protoplast release buffer 5 ( $1 \%$ Driselase with $1.0 \mathrm{~mol} / \mathrm{L}$ sorbitol in STC); protoplast release buffer 6 (mixture of 1\% Driselase and 1\% lysing enzyme with $1.0 \mathrm{~mol} / \mathrm{L}$ sorbitol in STC) were used to prepare protoplasts from mycelia. The hygromycin B $(\mathrm{HmB})$ was purchased from Takara Co. The PCR primers used in this test were synthesized by Sangon Biotech (Shanghai), Co., Ltd., Shanghai, China.

\subsection{Sensitivity of C. paradoxa to $\mathrm{HmB}$}

Hygromycin B (HmB) ranging from $10-40 \mu \mathrm{g} / \mathrm{mL}$ was used for testing the sensitivity of C. paradoxa to the antibiotic. Agar blocks $(5 \mathrm{~mm} \times 5 \mathrm{~mm})$ containing mycelia were cut from the edge of the $C$. paradoxa colonies grown on PDA plates and transferred into the center of new PDA plates supplemented with different concentrations of hygromycin $\mathrm{B}$ and incubated at $25^{\circ} \mathrm{C}$, PDA plates without $\mathrm{HmB}$ served as a control. The effect of $\mathrm{HmB}$ on $\mathrm{C}$. paradoxa growth was analyzed by measuring the diameter of growing mycelial on the plates after 5 days. The test was carried out in triplicate.

\subsection{Plasmid Extraction of $p C T 74$-sGFP}

The E. coli $\mathrm{DH} 5 \alpha$ construct containing $\mathrm{pCT74}$ was spread onto LB plates containing ampicillin Na (Amp, $100 \mu \mathrm{g} / \mathrm{mL}$ ). A single colony was inoculated into LB liquid medium containing $2 \mu \mathrm{L} 100 \mathrm{mg} / \mathrm{mL}$ Amp and incubated with shaking at $37{ }^{\circ} \mathrm{C}$ overnight. Plasmid extraction was achieved using a plasmid Mini Kit (Takara, Japan). Plasmids were detected by $1.5 \%$ agarose gel electrophoresis and the plasmid DNA concentration was measured using a Micro-Ultraviolet Spectrophotometer (NanoDrop 2000, Thermo Scientific, Waltham, MA, USA).

\subsection{Protoplast Preparation}

The entire procedure detailed below was performed under aseptic conditions. A 5-mm diameter agar disc from the growth margins of the X-3314 colony was placed in the center of a fresh PDA plate. After incubation at $25^{\circ} \mathrm{C}$ for 5 days, the colony had grown over and covered the plate. Ten milliliters of sterile water was added to the plate and the conidia of $C$. paradoxa were collected and adjusted to a concentration of $1 \times 10^{7}$ spores $\mathrm{mL}^{-1}$ with sterilized water using a hemocytometer prior to inoculation. Approximately $6 \mathrm{~mL}$ of $1 \times 10^{6}$ spores $\mathrm{mL}^{-1}$ conidia was inoculated into the SYM medium and distributed into three flasks, with $400 \mathrm{~mL}$ of medium per flask. The flasks were incubated at $25^{\circ} \mathrm{C}$ for $24 \mathrm{~h}$ under shaking at $60 \mathrm{rpm} / \mathrm{min}$. The mycelia were collected using two layers of micro-cloth (Calbiochem, Cambridge, MA, USA) and washed with sterilized water twice, followed by washing three times with $15 \mathrm{~mL}$ osmotic pressure stabilizer, and then dried on filter paper. One gram of mycelia was collected and thoroughly suspended in protoplast release buffer 2 at $31{ }^{\circ} \mathrm{C}$ with shaking at $90 \mathrm{rpm} / \mathrm{min}$ for $90 \mathrm{~min}$. Three layers of micro-cloth were placed in a $50-\mathrm{mL}$ sterilized centrifuge tube used for filtering the lysis solution, after which the filtrates were centrifuged at $4000 \mathrm{rpm}$ for $10 \mathrm{~min}$ at $4{ }^{\circ} \mathrm{C}$. After discarding the supernatant, the pellet was washed by gently re-suspending it in $20 \mathrm{~mL}$ STC and the same STC wash procedure was repeated twice. The concentration of the protoplasts was 
then adjusted to $6.0 \times 10^{7}-3.0 \times 10^{8} / \mathrm{mL}$ with STC. Finally, $20 \mu \mathrm{L}$ DMSO was added to the protoplast suspension, which was then distributed into $2 \mathrm{~mL}$ centrifuge tubes with $150 \mu \mathrm{L}$ of suspension per tube. The tubes were then stored at $-80^{\circ} \mathrm{C}$ until use.

\subsection{Protoplast Transformation}

Ten microliters of pCT74-sGFP plasmid DNA was added to $150 \mu \mathrm{L}$ of prepared protoplast suspension and gently mixed, and then incubated at $25^{\circ} \mathrm{C}$ for $30 \mathrm{~min}$. Following this, $600 \mu \mathrm{L}$ PTC was added and the solution was incubated at room temperature $\left(25^{\circ} \mathrm{C} \pm 1{ }^{\circ} \mathrm{C}\right)$ for $30 \mathrm{~min}$, after which $6 \mathrm{~mL}$ TB3 was added to the reaction tube $(50 \mathrm{~mL})$ and incubated at $25^{\circ} \mathrm{C}$ with shaking $(90 \mathrm{rpm})$ overnight. The treatment tube with liquid TB3 was mixed with $100 \mathrm{~mL}$ solid TB3 medium (that had been melted at $50{ }^{\circ} \mathrm{C}$ ) containing $80 \mu \mathrm{L}$ of a $40 \mu \mathrm{g} / \mathrm{mL} \mathrm{HmB}$ stock solution and poured into $15 \mathrm{~cm}$ diameter plates, which were then incubated at $25^{\circ} \mathrm{C}$ for 3-4 $\mathrm{d}$ in preparation for transformant growth detection.

\subsection{Screening for HmB Resistance and Stability Test}

The potential transformant colonies growing on $\mathrm{HmB}$ plates were used to inoculate selective PDA medium containing $80 \mu \mathrm{L}$ of a $40 \mu \mathrm{g} / \mathrm{mL} \mathrm{HmB}$ stock solution, with one plate for each potential transformant. These plates were then incubated at $25{ }^{\circ} \mathrm{C}$ for $4 \sim 5$ days. To confirm the stability of the transformants, they were inoculated on PDA plates lacking $\mathrm{HmB}$ and incubated at $25^{\circ} \mathrm{C}$ for $3 \mathrm{~d}$. The mycelia from the edge of the colonies were inoculated on fresh PDA plates for seven successive subcultures, and then transferred to selective PDA plates containing $80 \mu \mathrm{L}$ of a $40 \mu \mathrm{g} / \mathrm{mL} \mathrm{HmB}$ stock solution in order to observe the growth under selective conditions. The fluorescence of the transformants was monitored using a confocal microscope (Nikon C-HGFIE) with VC40 oil objective, and fluorescence was detected at $488 \mathrm{~nm}$.

\subsection{PCR Detection}

The primers were as follows: ToxAsGFPF, 5'TGGAATCCATGGAGGAGTTC3'; ToxAsGFPR, 5'CTTGTACAGCTCGTCCATGC3'. To determine whether the gfp gene had integrated into the genome, a pair of primers (ToxAsGFPF and ToxAsGFPR') were designed based on the ToxA promoter sequence and the sGFP sequence. Polymerase Chain Reaction (PCR) was used to confirm the integration of the GFP gene insert, with a predicted length of the amplified sequence containing the GFP of about $1.1 \mathrm{~kb}$. The genomic DNA of the transformants and wild-type strain was extracted using a modified cetyltrimethylammonium bromide (CTAB) method [26]. The pCT74-sGFP plasmid was regarded as a positive control. The PCR reaction system contained: $2.5 \mu \mathrm{L} 10 \times \mathrm{PCR}$ buffer, $2.5 \mu \mathrm{L} 2.5 \mathrm{mmol} / \mathrm{L}$ dNTPs, $1.0 \mu \mathrm{L}$ primerF, $1.0 \mu \mathrm{L}$ primerR, and $0.5 \mu \mathrm{LExtag}$. The PCR reaction procedure was as follows: $95^{\circ} \mathrm{C}$ for 3 min, followed by 35 cycles of $94{ }^{\circ} \mathrm{C}$ for $40 \mathrm{~s}, 64^{\circ} \mathrm{C}$ for $40 \mathrm{~s}, 72{ }^{\circ} \mathrm{C}$ for $80 \mathrm{~s}$, and a final extension at $72{ }^{\circ} \mathrm{C}$ for $10 \mathrm{~min}$.

\subsection{Pathogenicity Detection of the Transformants}

The wild strain X-3314 and positive transformants were cultured on PDA medium at $25^{\circ} \mathrm{C}$ for $5 \mathrm{~d}$. Coconut fruits ("Malayan Red Dwarf") were wounded and inoculated with a $1.5 \times 10^{5}$ spores $\cdot \mathrm{mL}^{-1}$ suspension of X-3314 or transformants. Wound incisions were made with a sterilized cork borer. The experiment was repeated in triplicate.

Author Contributions: X.N. and G.L. conceived and designed the research; X.W. and R.Z. participated in the specific design of the study; X.N. and C.L. performed the experiments and drafted the manuscript; F.Y., M.P. and H.Z. contributed reagents, materials; Y.L. participated in the preparation of the C. paradoxa protoplast; G.L. and W.Q. contributed analysis tools; All authors contributed to manuscript revision and approved the final version.

Funding: The present study was supported by Coconut Research Institute, Chinese Academy of Tropical Agricultural Sciences. This publication was supported by Key Laboratory of Biopesticide and Chemical Biology, Ministry of Education, Fujian Agriculture and Forestry University. This research was funded by Hainan Major Research Project for Science and Technology (zdjk201817), key project of Hainan Province (ZDYF2019072). 
Acknowledgments: The authors thank Zonghua Wang for his support in providing materials. Also thank Ya Li for his excellent technical guidance.

Conflicts of Interest: The authors declare no conflict of interest. The founding sponsors had no role in the design of the study; in the collection, analyses, or interpretation of data; in the writing of the manuscript; and in the decision to publish the results. The work described was original research that has not been published previously, and not under consideration for publication elsewhere, in whole or in part.

\section{References}

1. Alfieri, S.A., Jr. Stem bleeding disease of coconut palm, cocos nucifera L. Plant Pathol. Circ. 1967, 53, $250-251$.

2. Dulce, R.N.; Edson, E.M. Outbreak of stem bleeding in coconuts caused by Thielaviopsis paradoxa in Sergipe, Brazil. Trop. Plant Pathol. 2009, 34, 175-177.

3. Yu, F.Y.; Niu, X.Q.; Tang, Q.H.; Zhu, H.; Song, W.W.; Qin, W.Q.; Lin, C.H. First report of stem bleeding in coconut caused by Ceratocystis paradoxa in Hainan, China. Plant Dis. 2012, 96, 290. [CrossRef]

4. Niu, X.Q.; Yu, F.Y.; Fu, H.Q.; Qin, W.Q. Artificial inoculation techniques of coconut stem bleeding disease and screening of resistant sources of coconut. South China Fruits. 2015, 44, 44-46.

5. Yu, F.Y.; Lin, C.H.; Zhu, H.; Wang, P.; Chen, S.T.; Niu, X.Q.; Tang, Q.H. Biological characteristics of the pathogenic fungus causing stem bleeding disease of coconut. Chin. J. Trop. Crops. 2011, 32, 1122-1127.

6. Carvalho, R.R.; Souza, P.E.; Warwick, D.R.; Pozza, E.A.; Filho, J.L. Spatial and temporal analysis of stem bleeding disease in coconut palm in the state of Sergipe, Brazil. An. Acad. Bras. Cienc. 2013, 85, 1567-1576. [CrossRef] [PubMed]

7. Bhuiyan, S.A.; Croft, B.J.; Tucker, G.R. Efficacy of the fungicide flutriafol for the control of pineapple sett rot of sugarcane in Australia. Australas. Plant Path. 2014, 43, 413-419. [CrossRef]

8. Gowda, P.V.; Nambiar, K.N. Antifungal activity of garlic (Allium sativum Linn.) extracts on Thielaviopsis paradoxa(de Seynes) von Hohnel, the pathogen of stem bleeding disease of coconut. J. Plant Crops. 2006, 34, $472-475$.

9. Srinivasulu, B.; Kumar, K.V.; Aruna, K.; Lakshmi, M.V.; Rao, D.V.R. Biointensive IDM approach against basal stem rot and stem bleeding diseases of coconut. J. Plant Crops. 2006, 34, 502-507.

10. Rahman, M.A.; Begum, M.F.; Alam, M.F. Screening of Trichoderma isolates as a biological control agent against Ceratocystis paradoxa causing pineapple disease of sugarcane. Mycobiology 2009, 37, 277-285. [CrossRef]

11. Mustaffa, N.Z.N. Transformation of Fungal Endophyte, Ceratocystis paradoxa. Bachelor's Thesis, University of Malaysia Sarawak, Sarawak, Malaysia, July 2015.

12. Burns, C.; Gregory, K.E.; Kirby, M.; Cheung, M.K.; Riquelme, M.; Elliott, T.J.; Challen, M.P.; Bailey, A.; Foster, G.D. Efficient GFP expression in the mushrooms Agaricusbisporus and Coprinuscinereus requires introns. Fungal Genet. Biol. 2005, 42, 191-199. [CrossRef] [PubMed]

13. Lorang, J.M.; Tuori, R.P.; Martinez, J.P.; Sawyer, T.L.; Redman, R.S.; Rollins, J.A.; Wolpert, T.J.; Johnson, K.B.; Rodriguez, R.J.; Dickman, M.B.; et al. Green fluorescent protein is lighting up fungal biology. Appl. Environ. Microbe 2001, 67, 1987-1994. [CrossRef]

14. Horowitz, S.; Freeman, S.; Sharon, A. Use of green fluorescent protein-transgenic strains to study pathogenic and nonpathogenic lifestyles in Colletotrichum acutatum. Phytopathology 2002, 92, 743-749. [CrossRef]

15. Amey, R.C.; Atheypollard, A.; Burns, C.; Mills, P.R.; Bailey, A.; Foster, G.D. PEG-mediated and Agrobacterium-mediated transformation in the mycopathogenVerticillium fungicola. Mycol. Res. 2002, 106, 4-11. [CrossRef]

16. Pöggeler, S.; Masloff, S.; Hoff, B.; Mayrhofer, S.; Kück, U. Versatile GFP reporter plasmids for cellular localization of recombinant gene products in filamentous fungi. Curr. Genet. 2003, 43, 54-61. [PubMed]

17. Tanaka, A.; Shiotani, H.; Yamamoto, M.; Tsuge, T. Insertional mutagenesis and cloning of the genes required for biosynthesis of the host-specific AK-toxin in the Japanese pear pathotype of Alternaria alternata. Mol. Plant Microbe Interact. 1999, 12, 691-702. [CrossRef] [PubMed]

18. Lin, J.F.; Zheng, M.Y.; Wang, J.; Shu, W.; Guo, L.Q. Efficient transformation and expression of $g f p$ gene in the edible mushroom Pleurotus nebrodensis. Prog. Nat. Sci. 2008, 18, 819-824. [CrossRef]

19. Rajasekaran, K.; Cary, J.W.; Cotty, P.J.; Cleveland, T.E. Development of a GFP-Expressing Aspergillus flavus strain to study fungal invasion, colonization, and resistance in cottonseed. Mycopathologia 2008, 165, 89-97. [CrossRef] 
20. Vieira, A.L.; Camilo, C.M. Agrobacterium tumefasciens-mediated transformation of the aquatic fungus Blastocladiell aemersonii. Fungal Genet Biol. 2011, 48, 806-811. [CrossRef] [PubMed]

21. Cubitt, A.B.; Adams, S.R.; Boyd, A.E.; Gross, L.A.; Tsien, R.Y. Understanding, improving and using green fluorescent proteins. Trends Biochem. Sci. 1995, 20, 448-455. [CrossRef]

22. Chiu, W.L.; Niwa, Y.; Zeng, W.; Hirano, T.; Kobayashi, H.; Sheen, J. Engineered GFP as a vital reporter in plants. Curr. Biol. 1996, 6, 325-330. [CrossRef]

23. Andrie, R.M.; Martinez, J.P.; Ciuffetti, L.M. Development of ToxA and ToxB promoter-driven fluorescent protein expression vectors for use in filamentous ascomycetes. Mycologia 2005, 97, 1152-1161. [CrossRef] [PubMed]

24. Carroll, A.M.; Sweigard, J.M.; Valent, B. Improved vectors for selecting resistance to hygromycin. Fungal Genetics Newsletter. Fungal Genet. Newsl. 1994, 41, 22.

25. Ciuffetti, L.M.; Tuori, R.P.; Gaventa, J.M. A Single gene encodes a selective toxin causal to the development of tan spot of wheat. Plant Cell. 1997, 9, 135-144. [CrossRef] [PubMed]

26. Tendulkar, S.R.; Gupta, A.; Chattoo, B.B. A simple protocol for isolation of fungal DNA. Biotechnol. Lett. 2003, 25, 1941-1944. [CrossRef] [PubMed]

(C) 2019 by the authors. Licensee MDPI, Basel, Switzerland. This article is an open access article distributed under the terms and conditions of the Creative Commons Attribution (CC BY) license (http://creativecommons.org/licenses/by/4.0/). 